\title{
Effects of shade on the development and sugar metabolism of coffee (Coffea arabica L.) fruits
}

\author{
Clara Geromel ${ }^{\mathrm{a}}$, Lúcia Pires Ferreira ${ }^{\mathrm{b}}$, Fabrice Davrieux ${ }^{\mathrm{d}}$, Bernard Guyot ${ }^{\mathrm{d}}$, \\ Fabienne Ribeyre ${ }^{\mathrm{d}}$, Maria Brígida dos Santos Scholz ${ }^{\mathrm{b}}$, Luiz Filipe Protasio Pereira ${ }^{\mathrm{c}}$, \\ Philippe Vaast ${ }^{\mathrm{f}}$, David Pot ${ }^{\mathrm{b}, \mathrm{e}}$, Thierry Leroy ${ }^{\mathrm{e}}$, Armando Androcioli Filho ${ }^{\mathrm{b}}$, \\ Luiz Gonzaga Esteves Vieira ${ }^{b}$, Paulo Mazzafera ${ }^{a}$, Pierre Marraccini ${ }^{\text {be, }, *}$ \\ ${ }^{a}$ Departamento de Fisiologia Vegetal-IB, UNICAMP, CP 6109, 13083-970 Campinas, SP, Brazil \\ ${ }^{\mathrm{b}}$ IAPAR, LBI-AMG, CP 481, 86001-970 Londrina, PR, Brazil \\ ${ }^{\mathrm{c}}$ EMBRAPA Café-LBI, CP 481, 86047-902 Londrina, PR, Brazil \\ ${ }^{\mathrm{d}}$ CIRAD-UMR Qualisud, TA B-95/16, 73 rue JF Breton, 34398 Montpellier, France \\ ${ }^{\mathrm{e}}$ CIRAD-UMR DAP, Avenue d'Agropolis, 34398 Montpellier, France \\ ${ }^{\mathrm{f}}$ CIRAD-UPR 80, CATIE, Apdo 3, Turrialba, Costa Rica
}

Received 1 October 2007

Available online 4 March 2008

\begin{abstract}
Coffee fruits grown in shade are characterized by larger bean size than those grown under full-sun conditions. The present study assessed the effects of shade on bean characteristics and sugar metabolism by analyzing tissue development, sugar contents, activities of sucrose metabolizing enzymes and expression of sucrose synthase-encoding genes in fruits of coffee (Coffea arabica L.) plants submitted to full-sun (FS) and shade $(\mathrm{SH})$ conditions. Evolution of tissue fresh weights measured in fruits collected regularly from flowering to maturation indicated that this increase is due to greater development of the perisperm tissue in the shade. The effects of light regime on sucrose and reducing sugar (glucose and fructose) contents were studied in fresh and dry coffee beans. Shade led to a significant reduction in sucrose content and to an increase in reducing sugars. In pericarp and perisperm tissues, higher activities of sucrose synthase (EC 2.4.1.13) and sucrose-phosphate synthase (SPS: EC 2.4.1.14) were detected at maturation in the shade compared with full sun. These two enzymes also had higher peaks of activities in developing endosperm under shade than in full sun. It was also noted that shade modified the expression of SUS-encoding genes in coffee beans; CaSUS2 gene transcripts levels were higher in SH than in FS. As no sucrose increase accompanied these changes, this suggests that sucrose metabolism was redirected to other metabolic pathways that need to be identified.
\end{abstract}

(C) 2008 Elsevier Masson SAS. All rights reserved.

Keywords: Bean composition; Coffea arabica; Fruit development; Gene expression; Shade; Sucrose synthase; Sugar metabolism

\section{Introduction}

Sucrose represents the major transport form of photosynthetically assimilated carbon in plants and its metabolism plays

Abbreviations: DAF, days after flowering; FS, full sun; NIRS, near infrared reflectance spectroscopy; $\mathrm{SH}$, shade.

* Corresponding author at present address: EMBRAPA-Center of Genetic Resources and Biotechnology, Parque Estação Biológica, CP 02372, 70770900 Brasilia (DF), Brazil. Tel.: +55 613448 4795; fax: +55 6133403624 .

E-mail address: marraccini@cirad.fr (P. Marraccini). a key role, particularly in sink tissues such as fruits [23]. The key enzymes of sucrose metabolism are invertases (EC 3.2.1.26, $\beta$-fructosidase, $\beta$-fructofuranosidase), sucrose phosphate synthase (SPS; UDP-glucose: D-fructose 6-phosphate 2-glucosyl-transferase) and sucrose synthase (SUS; UDPglucose: D-fructose 2-glucosyl-transferase). Invertases catalyze the irreversible hydrolysis of sucrose to glucose and fructose; they are also involved in plant responses to environmental stimuli [34]. In contrast, SPS functions mainly in sucrose synthesis (UDP-glucose + fructose-P $\rightarrow$ sucrose-P + UDP), 
whereas SUS catalyses a reversible reaction (UDP-glucose + fructose $\leftrightarrow$ sucrose + UDP). Both enzymes are thought to play a major role in sucrose partitioning for energy purposes as well as in metabolic, structural and storage functions in plant cells [39]. The sucrolytic activity of SUS is also linked to cell wall biosynthesis by providing UDP-glucose for the cellulose synthase complex [3] and substrates for starch synthesis in sink organs [18]. In contrast, an increase in SUS activity associated with sucrose accumulation was reported in several fruits such as peach, citrus and muskmelon [19,20,25,26].

In coffee and many other plants, sucrose is essential for the control of sink-source mechanisms [11]. Sucrose is also one of the main compounds in coffee beans, varying from 5\% to $9.5 \%$ of dry matter basis $(\mathrm{dmb})$ in Coffea arabica and from $4 \%$ to $7 \%$ of dmb in Coffea canephora [22]. Although considerably degraded during bean roasting, sucrose remains noticeably present in roasted grains at concentrations of $0.4-2.8 \%$ $\mathrm{dmb}$ and is likely to contribute to beverage sweetness [17]. It is also the main contributor of reducing sugars which are implicated in Maillard reactions occurring during the roasting process [15]. The higher sucrose contents in Arabica green bean could partially explain its better cup quality [22].

Coffee beverage quality also depends on various environmental factors, including shade [4,9]. Artificial shade [1] or shade trees [5] reduce coffee fruit load through their effects on coffee physiology, such as longer internodes, fewer fruiting nodes and lower flower induction. In contrast, shade results in beans of larger size [27]. Altogether, this leads to higher coffee quality, probably by lowering tree stress, which favors slow fruit ripening and hence better bean filling [42]. The effect of shade on sucrose content in mature beans has also been documented, but remains controversial. Increased sucrose content was reported for the Catuai cultivar of C. arabica grown under shade conditions [17], whereas a negative relationship between sucrose and shade was observed for the Catimor cultivar of $C$. arabica [42]. Sucrose content in coffee beans also seems to depend on the particular $C$. arabica cultivar since a positive correlation was observed between altitude and sucrose for Catuai but not for Bourbon [17]. Sucrose accumulation in developing coffee fruit was first studied in C. canephora by Guyot et al. [16] who showed that bean sucrose content varied with the maturation degree and ripening speed; sucrose content was found to increase from green to red-violet cherries and had lower values in precocious fruits than in late fruits. More recently, sucrose metabolism and the role of sucrose synthase were investigated during development in the fruit tissues (pericarp, perisperm and endosperm) of $C$. arabica L. cv. IAPAR 59 [12], a "Sarchimor" cultivar derived from a cross between Villa Sarchi (CIFC 971/10) cultivar and Timor hybrid (CIFC 832/2) [37]. This study highlighted the importance of the pericarp and perisperm tissues in providing sugar precursors for endosperm development and identified SUS as one of the main enzymes responsible for sucrose accumulation in mature beans.

Despite the rapid development of coffee specialty markets, in-depth studies of shade effects on coffee bean metabolism are yet to be undertaken. The aim of this work was to initiate such analyses on tissue evolution, sucrose content, activities of sucrose-metabolizing enzymes and gene expression in developing fruits of plants grown under shade $(\mathrm{SH})$ and full-sun (FS) conditions. Using the same cultivar (C. arabica $\mathrm{L}$. cv. IAPAR 59) as that studied in our previous work on sucrose metabolism in developing fruits grown under FS field conditions [12], the present study is the first to investigate this with respect to sucrose metabolism in developing fruits of plants grown under SH and FS conditions. The results presented here are of general interest, particularly for distinguishing shade effects from other factors.

\section{Materials and methods}

\subsection{Plant material}

Fifteen-year-old plants of Coffea arabica $\mathrm{L}$. cv. IAPAR 59 [37] were cultivated ( $2 \mathrm{~m}$ between rows $\times 1 \mathrm{~m}$ within rows) at the experimental station of the Agronomic Institute of Paraná State (Iapar, Londrina, Brazil) in FS condition without irrigation. For the shade plot $(\mathrm{SH})$, light was artificially reduced using a black net $(30 \mathrm{~m} \times 20 \mathrm{~m})$ covering about 150 plants and allowing $50 \%$ of the photosynthetic photon flux density (PPFD). The net was installed over the plants 1 month after the main flowering, which occurred between 21 and 24 September, 2003. Weeds were controlled manually and plants were equally fertilized in both plots.

\subsection{Fruit sampling and processing}

In FS and SH conditions, fruits were harvested every four weeks after flowering until cherry fruit maturity. For the shade plot, fruits from plants of border lines were not collected. After collection, fruits were immediately frozen in liquid nitrogen and stored at $-80^{\circ} \mathrm{C}$. To ensure developmental synchrony of harvested fruits, cross sections were made to visually inspect the tissues (pericarp, perisperm and endosperm) that were separated and frozen for further analyses. The mature stage corresponded to cherry fruits with red pericarp turning to purple and containing hard white endosperm with the remaining perisperm forming a thin brown pellicle surrounding the endosperm.

Sugar quantification and enzymatic analyses were performed using one bulked sample $(100 \mathrm{~g})$ of fruits from ten plants randomly chosen within the plots. For physical and biochemical analyses of dry beans, three sets $(1.5 \mathrm{~kg})$ of $5-7$ plants each were harvested for the FS and SH plots for two different dates: 214 and 281 days after flowering (DAF). In order to compare SH and FS mature fruits, only ripe fruits were harvested (over-ripe cherries with a dried pericarp turning brown to black, were not considered). Fruits from the two harvests were then sun-dried for 15-20 days until beans reached 10-12\% humidity levels. Next, dried pericarp and endocarp (parchment) were mechanically removed. Bean density was measured by weighing three sub-samples (100 beans each) and measuring water displacement (with $0.1 \%$ Tween-20) in 
a $100 \mathrm{ml}$ test tube. Bean size distribution was also evaluated using a series of sieves with round perforations ranging from 4.8 to $7.1 \mathrm{~mm}$ [35].

\subsection{Weight measurements and tissue separation}

Fresh weights (FW) were evaluated after each harvest from three samples of 30 fruits at 32 and 60 DAF and from 10 fruits at later harvests which were discarded after weighing. For tissue dissections, three samples of 10 fruits frozen at $-80{ }^{\circ} \mathrm{C}$ were used and FW was measured throughout fruit development with a precision balance, except for small fruits (diameter $<2 \mathrm{~mm}$ ), for which tissue separation was not possible. Pericarp and endosperm tissues were separated beginning at 60 and 120 DAF respectively, up to the mature stage. Due to its tight adhesion to the endosperm in the latest maturation stages, perisperm tissue was not separated after 175 and 231 DAF in FS and SH conditions, respectively.

\subsection{Biochemical and enzymatic analyses}

Tissues of developing fruits grown under FS and SH conditions were freeze-dried, ground with a mortar and pestle and extracted with $80 \%$ ethanol in a Polytron homogenizer using $1 \mathrm{ml}$ per $300 \mathrm{mg}$ of tissue. Extraction proceeded for $30 \mathrm{~min}$ at $75{ }^{\circ} \mathrm{C}$ in cap-sealed tubes; supernatants were obtained after centrifugation. The extraction was carried out three times with the same volume of ethanol, and the combined supernatants were then used for the analysis of sugars. Sucrose content was determined according to Van Handel [43]. Levels of reducing sugars (RS: glucose and fructose) were determined according to Somogyi [38]. Lipid and trigonelline contents were measured by NIRS using dry beans $(20-30 \mathrm{~g})$ that had been equilibrated (for 6 days at $60 \%$ humidity and $\left.28{ }^{\circ} \mathrm{C}\right)$ prior to being frozen in liquid nitrogen and ground $(<0.5 \mathrm{~mm}$ ). The absorption spectrum (from 400 and $2500 \mathrm{~nm}$ ) of the powder was measured (NIRS model 6500, NIRS System Inc., Silver Spring, MD) and compared with previously established calibration curves [9]. Data were treated by Winisi 1.5 (NIRS2 4.0) software (Intrasoft Int., Port Matilda, PA). Caffeine, chlorogenic acids (CGA), protein and tannin contents were evaluated according to the methods described in AOAC [2].

For the enzymatic analyses, proteins were extracted with $100 \mathrm{mM}$ HEPES (pH 7.0), containing $2 \mathrm{mM} \mathrm{MgCl}_{2}, 10 \mathrm{mM}$ 2-mercaptoethanol and $2 \%(\mathrm{w} / \mathrm{v})$ ascorbic acid to avoid oxidation. The supernatant recovered by centrifugation $(27,000 \times g$ for $20 \mathrm{~min}$ ) was desalted on PD10 minicolumns (Amersham Biosciences) and the protein content was determined with a ready-to-use [7] reagent (BioRad). Acid invertase (AI) activity, regrouping vacuolar (soluble) and cell wall invertase (insoluble) [39] levels were assayed by incubating an aliquot of the desalted extract containing $60 \mu \mathrm{g}$ of protein with $25 \mathrm{mM}$ sucrose in $50 \mathrm{mM}$ citrate-phosphate buffer $\left(\mathrm{pH} \mathrm{3.5)}\right.$ ) at $37^{\circ} \mathrm{C}$ for $1 \mathrm{~h}$ modified from Yelle et al. [47]. Levels of the resulting reducing sugars were determined as described before [38]. Sucrose phosphate synthase (SPS) activity was assayed in the direction of sucrose-phosphate synthesis by incubating $60 \mu \mathrm{g}$ of protein with $25 \mathrm{mM}$ uridine $5^{\prime}$-diphosphoglucose (UDPG), $25 \mathrm{mM}$ fructose-6-phosphate, $30 \mathrm{mM}$ glucose-6-phosphate, $20 \mathrm{mM}$ phenyl- $\beta$-glucoside in $50 \mathrm{mM}$ K-phosphate buffer (pH 7.5) for $1 \mathrm{~h}$ at $37^{\circ} \mathrm{C}$. Sucrose synthase (SUS) activity was assayed $\left(60 \mathrm{~min}\right.$ at $\left.30^{\circ} \mathrm{C}\right)$ in the direction of sucrose synthesis in a reaction containing $50-60 \mu \mathrm{g}$ of protein, $25 \mathrm{mM}$ UDPG, $25 \mathrm{mM}$ D-fructose and $50 \mathrm{mM}$ 2-( $N$-morpholino)ethanesulfonic acid hydrate (MES) (pH 6.0). Enzymatic reactions were stopped by the addition of $30 \%$ (w/v) $\mathrm{KOH}$ and boiling for $10 \mathrm{~min}$. The amounts of sucrose phosphate and sucrose formed in the SPS and SUS reactions were determined as described before [43]. Results of sugar contents and enzymatic activities are the mean \pm standard deviation (SD) of assays using three independent extractions.

\subsection{Northern blot analysis}

Total RNA was extracted from the endosperm of coffee fruits grown under FS and SH conditions, as described previously [32]. Fifteen micrograms of total RNA were fractionated on a $1.2 \%(\mathrm{w} / \mathrm{v})$ agarose gel containing $2.2 \mathrm{M}$ formaldehyde in MOPS buffer, transferred to Hybond N+ membranes (Amersham Biosciences) and hybridized independently with CaSUS1 and CaSUS2 probes, as previously described [12]. Amounts of RNA samples loaded were controlled by the equal abundance of $18 \mathrm{~S}$ and $26 \mathrm{~S}$ rRNA on gels stained with ethidium bromide.

\subsection{Statistical analysis}

All statistical analyses were performed with $\mathrm{R}$ software [30]. Comparisons of the bean size distribution between the two light regimes were performed for each harvest date using Pearson's chi-square tests. The amounts of biochemical compounds in the dried beans expressed as a percentage of fruit dry weight were transformed as "arcsin $\sqrt{ }$ percentage" before statistical analysis to reach a normal distribution of residues. The effects of light treatments, harvest dates and interaction of these factors on physical properties (weight, volume and density) and fruit chemical composition of the dried beans were evaluated through a two-fixed-factor ANOVA model with interaction.

\section{Results}

\subsection{Influence of shade on coffee fruit development}

Under the present conditions, shade delayed fruit ripening by approximately one month, with a full ripening of fruits estimated at $231 \mathrm{DAF}$ and $260 \mathrm{DAF}$ for FS and SH conditions, respectively (Fig. 1A). For mature fruits, no difference in total fruit fresh weight $(\mathrm{FW})$ was observed between FS $(1.40 \pm 0.15 \mathrm{~g})$ and $\mathrm{SH}(1.39 \pm 0.11 \mathrm{~g})$ conditions. Pericarp FW followed a biphasic curve, with a first peak at 87 DAF and a second peak at 197 DAF (Fig. 1B). Pericarp FW were similar between 60 and 144 DAF for FS and SH plants 

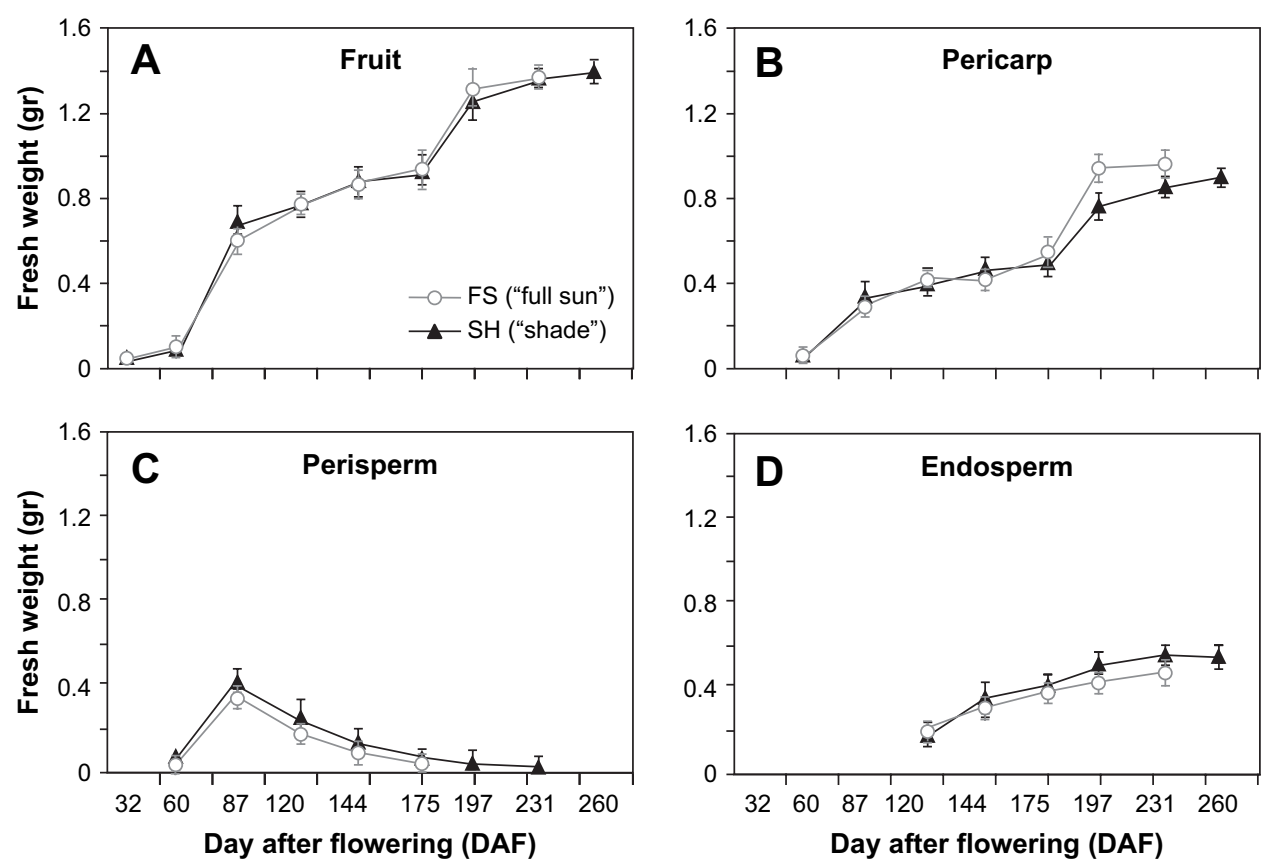

Fig. 1. Tissue evolution during the ripening process of C. arabica fruits grown under different light conditions. Fresh weights are given in grams for entire fruits (A), pericarp (B), perisperm (C) and endosperm (D) tissues. Open circles and closed triangles are for full-sun (FS) and shade (SH), respectively. Error bars indicate standard deviation $(\mathrm{SD})$ of repetitions $(n=3)$.

(Fig. 1B), whereas faster growth and higher pericarp FW were achieved in the FS compared to the SH conditions. Perisperm expansion was rapid between 60 and $87 \mathrm{DAF}$; FW was higher under SH conditions than it was in FS (Fig. 1C). After 87 DAF, the perisperm tissue disappeared gradually up to maturation, but remained separable from the endosperm for a longer period in SH fruits. The endosperm became easily detachable from the perisperm at $120 \mathrm{DAF}$. After this point, endosperm FW was always higher in SH than in FS fruits, reaching $0.51 \pm 0.07 \mathrm{~g}$ and $0.47 \pm 0.03 \mathrm{~g}$, respectively, at harvest (Fig. 1D).

\subsection{Effect of shade on bean characteristics}

Bean size distribution presented significant differences between light regimes, with a higher proportion of larger beans in SH than in FS conditions, for both harvest dates (Table 1A). These values were confirmed by a chi-square test. Light condition (LC) had a significant effect on both bean weight $(F=20.41, P<0.01)$ and volume $(F=19.54$, $P<0.01)$ (Table 1B). However, bean density was not affected by light conditions $(F=0.07, P>0.05)$. The harvest date effect and the interaction between light conditions and harvest date effect were not significant for these traits. In contrast, bean weight $(F=0.36, P>0.05)$, volume $(F=0.08$, $P>0.05)$ and density $(F=0.27, P>0.05)$ did not vary significantly with harvest date (HD).

\subsection{Effects of shade on sugars and other biochemical compounds}

Statistical analysis revealed that LC had no effects on total sugars $(F=4.47, P>0.05)$, but significantly affected the reducing sugar $(F=11.05, P<0.05)$ and sucrose contents $(F=6.59, P<0.05)$ of dry beans (Table 2$)$. While sucrose content was higher in FS than in SH conditions, the opposite was observed for reducing sugars. It is also worth noting that HD had a significant effect on RS $(F=14.02$,

Table 1A

Size distribution (expressed in \%) of mature beans of C. arabica L. cv. IAPAR 59 under full sun (FS) and shade (SH)

\begin{tabular}{|c|c|c|c|c|c|c|}
\hline \multirow[t]{3}{*}{ Harvest time } & \multicolumn{6}{|c|}{ Bean diameter $(\mathrm{mm})$} \\
\hline & \multicolumn{2}{|l|}{$<5.9$} & \multicolumn{2}{|l|}{$5.9-6.8$} & \multicolumn{2}{|l|}{$\geq 6.8$} \\
\hline & FS & SH & FS & SH & FS & SH \\
\hline $281 \mathrm{DAF}$ & $22.8 \pm 4.1$ & $12.4 \pm 2.1$ & $71.2 \pm 2.9$ & $68.2 \pm 3.4$ & $5.9 \pm 1.7$ & $19.8 \pm 1.6$ \\
\hline Chi-square test $214 \mathrm{DAF}$ & \multicolumn{6}{|c|}{$\chi^{2}=13.6321, P$ value $(\mathrm{df}=2)=0.001096^{* *}$} \\
\hline Chi-square test $281 \mathrm{DAF}$ & \multicolumn{6}{|c|}{$\chi^{2}=10.5534, P$ value $(\mathrm{df}=2)=0.005109^{* *}$} \\
\hline
\end{tabular}

Values of Pearson's chi-square tests and the corresponding $P$-values are indicated. 
Table 1B

Weight, volume and density values of mature beans of $C$. arabica L. cv. IAPAR 59 under full sun (FS) and shade (SH)

\begin{tabular}{|c|c|c|c|c|c|c|c|c|c|}
\hline \multirow[t]{2}{*}{ Harvest time } & \multicolumn{3}{|l|}{ Weight (g) } & \multicolumn{3}{|c|}{ Volume $\left(\mathrm{cm}^{3}\right)$} & \multicolumn{3}{|c|}{ Density $\left(\mathrm{g} \mathrm{cm}^{-3}\right)$} \\
\hline & FS & & $\mathrm{SH}$ & FS & & $\mathrm{SH}$ & FS & & $\mathrm{SH}$ \\
\hline $214 \mathrm{DAF}$ & $12.7 \pm 0.7$ & & $13.8 \pm 0.4$ & $18.8 \pm 1.0$ & & $20.5 \pm 0.8$ & $0.68 \pm 0.01$ & & $0.68 \pm 0.03$ \\
\hline $281 \mathrm{DAF}$ & $12.4 \pm 0.4$ & & $13.8 \pm 0.3$ & $18.3 \pm 0.6$ & & $20.7 \pm 0.6$ & $0.68 \pm 0.00$ & & $0.67 \pm 0.03$ \\
\hline$F$-value LC & & $20.41 * *$ & & & $19.54 * *$ & & & $0.07^{\mathrm{ns}}$ & \\
\hline$F$-value HD & & $0.36^{\mathrm{ns}}$ & & & $0.08^{\mathrm{ns}}$ & & & $0.27^{\mathrm{ns}}$ & \\
\hline$F$-value $\mathrm{LC} \times \mathrm{HD}$ & & $0.44^{\mathrm{ns}}$ & & & $0.48^{\mathrm{ns}}$ & & & $0^{\mathrm{ns}}$ & \\
\hline
\end{tabular}

Data were transformed as arcsin $\sqrt{ }$ percentage to perform the ANOVA analysis. $F$-values for light conditions (LC), harvest date (HD) and light condition $\times$ harvest date effects $(\mathrm{LC} \times \mathrm{HD})$ are indicated. ${ }^{\mathrm{ns}} P>0.05, * P<0.05, * * P<0.01$.

$P<0.01$ ); a lower content was observed at $281 \mathrm{DAF}$ than at 214 DAF. No LC $\times$ HD effects were observed on sugar contents. Dry bean contents of caffeine, chlorogenic acids (CGA), proteins, lipids, tannins and trigonelline were also investigated (Table 3). Light condition (LC) had a significant effect on lipids $(F=16.83, P<0.01)$, where higher values were observed in FS relative to the SH condition. For the tannins, significant effects of light condition, harvest date and their interaction were observed. Contents of other compounds were not significantly affected by either light conditions or harvest dates.

Evolution of sucrose and reducing sugar (RS) contents was also measured in pericarp, endosperm and perisperm tissues of $\mathrm{SH}$ and FS fruits over the course of maturation. Irrespective of light treatments, the RS content of the pericarp was low from flowering to $175 \mathrm{DAF}$; it increased suddenly afterwards, reaching a higher value under SH than in FS conditions (404 vs. $326 \mathrm{mg} \mathrm{g}^{-1}$ dry weight (DW), respectively) (Fig. 2A). Under both light conditions, sucrose content in the pericarp followed a similar trend, with a great increase after 175 DAF, reaching similar values (close to $85 \mathrm{mg} \mathrm{g}^{-1} \mathrm{DW}$ ) at harvest (Fig. 2D). In the endosperm, high RS and low sucrose levels were observed under both light conditions between 120 and 175 DAF, which corresponds to the expansion phase of this tissue (Fig. 2B and E). After 197 DAF, RS content decreased gradually, becoming negligible by the mature stage, whereas sucrose content increased suddenly, reaching a peak $\left(\approx 73 \mathrm{mg} \mathrm{g}^{-1} \mathrm{DW}\right)$ at $231 \mathrm{DAF}$ under both FS and SH conditions. As in the pericarp, a slight but significant decline in sucrose content was observed during the last month of maturation under shade. In the perisperm, RS content was higher in SH than in FS conditions (Fig. 2C), while no major differences in sucrose contents were observed (Fig. 2F).

\subsection{Enzymatic activities}

\subsubsection{Enzymatic activities in the pericarp tissue}

SUS activity in the pericarp exhibited varying patterns depending on the light regime. In the FS condition, activity increased continuously from 60 to 197 DAF and diminished thereafter until the harvest (Fig. 3A). Under SH condition, two peaks of similar levels were observed at 144 and 197 DAF. At harvest, SUS activity was higher in the SH than in the FS conditions.

SPS activity profiles were similar to those of SUS (Fig. 3B). Maximum activities were observed at 197 DAF, with higher activities in the FS than in the SH condition. In both treatments, SPS activities diminished between 197 and 231 DAF. At harvest, higher SPS activity was observed in the SH than in the FS condition. Invertase profiles appeared similar during pericarp development under both light conditions, with peaks of activity of comparable amplitude (Fig. 3C). Under shade conditions, AI activity declined rapidly after $231 \mathrm{DAF}$, becoming undetectable at harvest. At this time, FS pericarp exhibited higher AI activity than those from $\mathrm{SH}$.

\subsubsection{Enzymatic activities in the perisperm tissue}

In both treatments, SUS activity was low during early developmental stages of the perisperm up to 120 DAF (Fig. 4A); activity increased thereafter, reaching a peak that had a higher value in the SH (197 DAF) than in the FS (175 DAF) conditions. In the shade, SUS decreased notably, down to $2.91 \pm 0.22 \mu \mathrm{g}$ sucrose $\mu \mathrm{g}$ protein ${ }^{-1} \mathrm{~h}^{-1}$ at $231 \mathrm{DAF}$. The activity profiles of SPS also followed those of SUS in both light regimes (Fig. 4B). Under shade, SPS activity reached a maximum value at $197 \mathrm{DAF}$ which was twice that observed at 144 DAF under FS condition (Fig. 4B). After this point, SPS

Table 2

Reducing sugar and sucrose contents in mature beans of $C$. arabica L. cv. IAPAR 59 under full-sun (FS) and shade (SH) conditions

\begin{tabular}{|c|c|c|c|c|c|c|c|c|c|}
\hline \multirow[t]{2}{*}{ Harvest time } & \multicolumn{3}{|l|}{ Total sugars } & \multicolumn{3}{|c|}{ Reducing sugars } & \multicolumn{3}{|l|}{ Sucrose } \\
\hline & FS & & SH & FS & & SH & FS & & SH \\
\hline $214 \mathrm{DAF}$ & $8.79 \pm 0.11$ & & $8.59 \pm 0.15$ & $0.33 \pm 0.03$ & & $0.47 \pm 0.01$ & $8.46 \pm 0.10$ & & $8.12 \pm 0.16$ \\
\hline $281 \mathrm{DAF}$ & $8.70 \pm 0.39$ & & $8.04 \pm 0.56$ & $0.19 \pm 0.03$ & & $0.31 \pm 0.13$ & $8.51 \pm 0.37$ & & $7.73 \pm 0.64$ \\
\hline$F$-value LC & & $4.47^{\mathrm{ns}}$ & & & $11.05^{*}$ & & & $6.59 *$ & \\
\hline$F$-value HD & & $2.43^{\mathrm{ns}}$ & & & $14.02 * *$ & & & $0.58^{\text {ns }}$ & \\
\hline$F$-value $\mathrm{LC} \times \mathrm{HD}$ & & $1.29^{\mathrm{ns}}$ & & & $0.09^{\mathrm{ns}}$ & & & $1.01^{\mathrm{ns}}$ & \\
\hline
\end{tabular}

For both conditions, two harvests were evaluated: 214 DAF and 281 DAF. Values are given in $\%$ of bean dry weight (DW). F-values are indicated for LC (light condition) and HD (harvest date) and $\mathrm{LC} \times \mathrm{HD}$ effects. ${ }^{\text {ns }} P>0.05, * P<0.05, * * P<0.01$. 


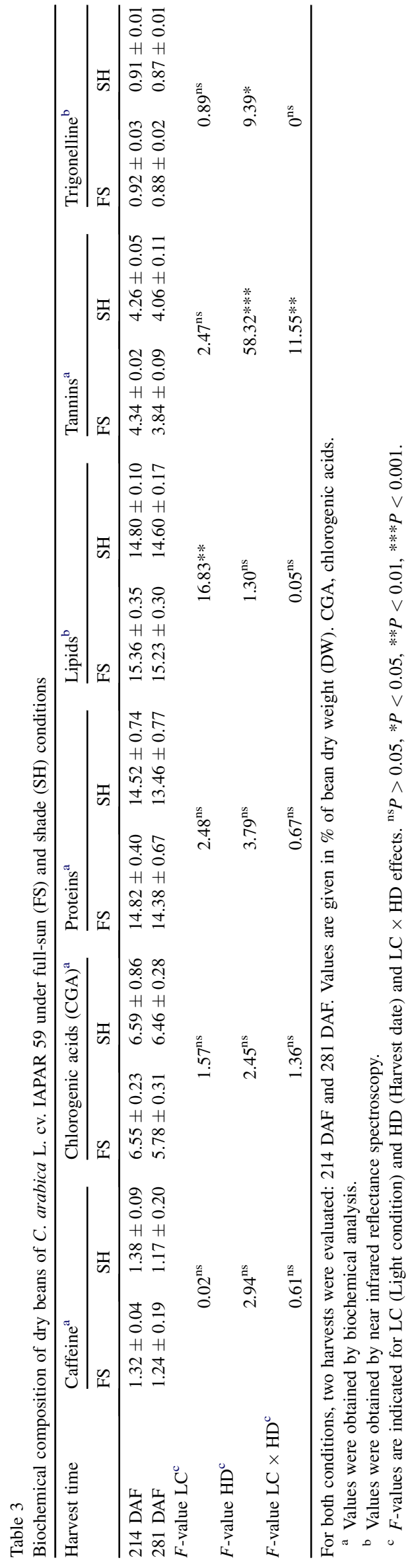

activity declined steeply, down to a value of 231 DAF which was similar to that observed in FS at 175 DAF. AI activity was higher in the FS than in the SH conditions during early developmental stages; activity increased greatly between 144 and 231 DAF in SH (Fig. 4C). However, as long as it was possible to separate the perisperm tissue, AI activity always remained undetectable after 87 DAF in FS condition.

\subsubsection{Enzymatic activities in endosperm tissue}

Under both light conditions, SUS activity was low in young endosperm, but increased during later developmental stages (Fig. 5A). In the FS condition, SUS activity reached a maximum at $175 \mathrm{DAF}$ and decreased at harvest. Under shade, SUS activity increased towards the end of maturation and appeared three-fold higher than in the FS condition. SPS activity exhibited a peak at 144 DAF and diminished thereafter until harvest under full sun (Fig. 5B). In contrast, SPS activity increased regularly between 120 and 197 DAF in SH endosperm, declined between 197 and 231 DAF and increased greatly thereafter, with the highest value being observed at harvest. Irrespective of the light conditions, AI activities during endosperm development were always very low (Fig. 5C).

\subsection{Expression of SUS genes in endosperm of FS and $S H$ coffee fruits}

Light conditions modified steady-state levels of SUS-encoding genes in the endosperm (Fig. 6). Using probes specific for CaSUS1 and CaSUS2 mRNA from C. arabica, it was observed that CaSUS1 transcripts were weakly detectable during early development (120 DAF); then levels strongly increased at 144 DAF and diminished thereafter, becoming undetectable at the harvest under FS condition. Under shade, maximum CaSUS1 expression was detected at an early stage (at 120 DAF) than in FS, and then decreased gradually thereafter. In both light conditions, CaSUS2 transcripts were barely detected during endosperm development and accumulated at maturation, reaching a higher level in the SH than in the FS condition.

\section{Discussion}

\subsection{Effects of light regime on coffee fruit development}

The present results confirmed the importance of light regime in controlling the final bean characteristics. We demonstrated that shade delayed the development and maturation of coffee fruits for at least 1 month, without affecting fruit FW, which was similar in both light regimes. At the tissue level, shade reduced pericarp FW and thickness (data not shown), but increased endosperm (bean) $\mathrm{FW}$ at harvest, as confirmed by the increase of approximately $10 \%$ of the bean weight and volume in the SH compared with the FS treatment. These values are in the same range as previously reported [27]. We also showed an inverse relationship between pericarp and endosperm FW with light regimes. The importance of pericarp 

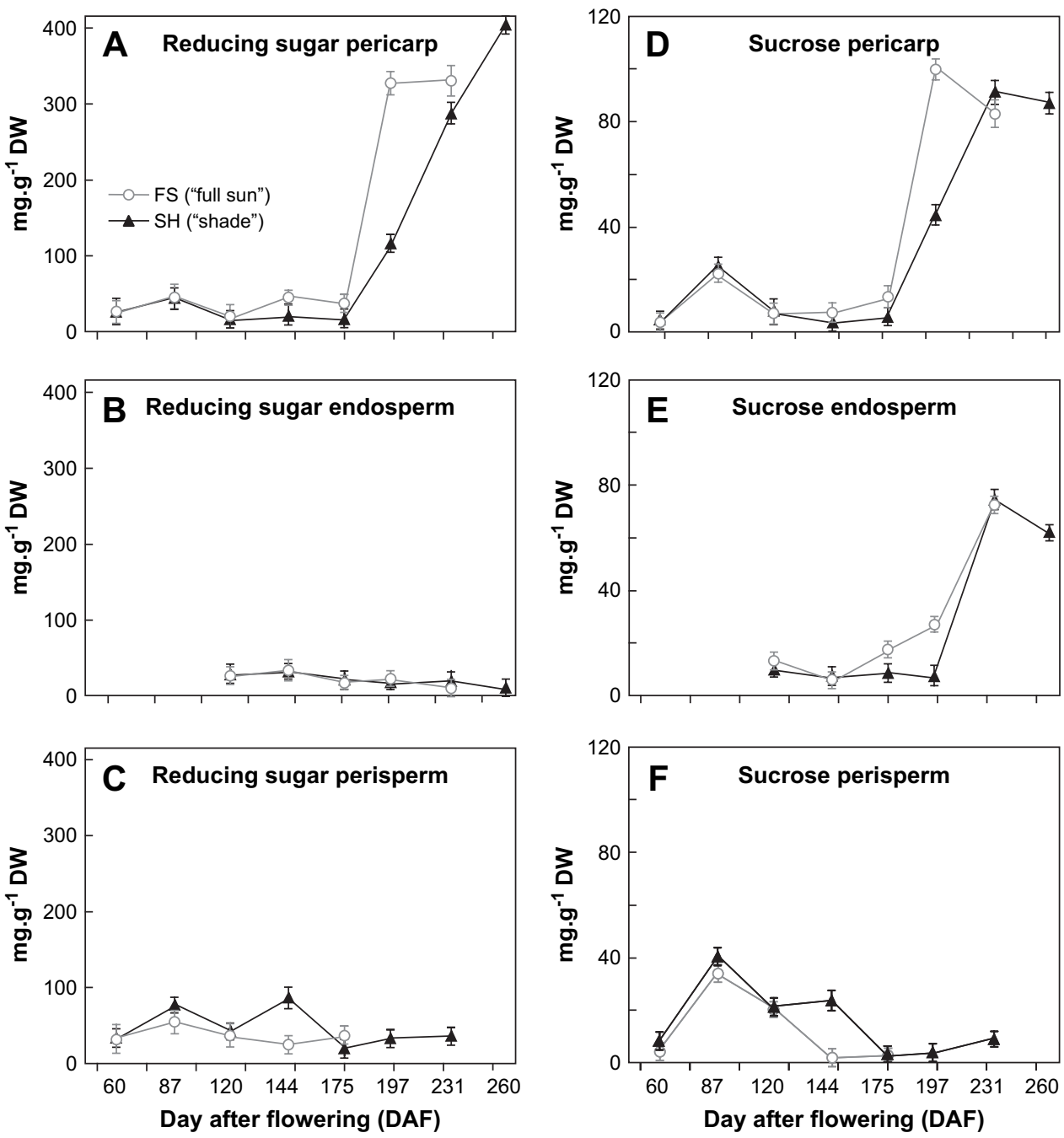

Fig. 2. Evolution of reducing sugars and sucrose contents in separated tissues from fruits of $C$. arabica L. cv. IAPAR 59 plants grown under full-sun (FS) and shade (SH). Data are expressed as $\mathrm{mg} \mathrm{g}^{-1}$ of dry weight (DW) for reducing sugars (A-C) and sucrose (D-F) in pericarp, perisperm and endosperm tissues. Open circles and closed triangles are for full-sun (FS) and shade (SH), respectively. Error bars indicate standard deviation (SD) of repetitions $(n=3)$.

in coffee berry photosynthesis is far from negligible, especially in view of the large berry sink strength and the finding that the berry photosynthetic area represents up to $20 \%$ of the total tree photosynthetic area at the highest fruit load [41]. Even if leaf photosynthesis contributed more to seed development than to the pericarp in terms of photosynthate supply, pulse-chase experiments with ${ }^{14} \mathrm{CO}_{2}$ and ${ }^{14} \mathrm{C}$-sugars also revealed the importance of the pericarp in terms of photosynthate supply to the endosperm [12]. Altogether, these results reinforce the idea that slowing down the ripening process by shade favors bean filling [42].

In plant seeds, high ratios of reducing sugar (RS) to sucrose (S) contents are characteristic of intensive cell division in young tissues [45]. The transition of the pre-storage phase to the maturation (storage) phase is then accompanied by a switch in carbohydrate state, from a high to low RS/S ratio. In coffee, the role of the perisperm, during the expansion, in determining the final size of the locular space, has been proposed $[8,31]$. Here, we have demonstrated that the perisperm is larger in
SH fruits than in FS fruits. This is probably a consequence of the maintenance of high RS/S ratios, thereby explaining the large bean size observed under the SH condition. At this time, we do not know if the increased size of the perisperm resulted from higher cell number, higher cell volume or a combination of both. The same question also applies to the endosperm. Because shade was artificially applied by a net installed over the plants one month after flowering, it is probable that the increase in bean size results from development of larger cell size rather than from an increase in cell number. Therefore, histological studies and detailed analyses of polysaccharide composition of SH and FS coffee fruits are worth undertaking to address this question.

\subsection{Effects of light regime on coffee fruit composition}

Light experienced by coffee plants modified the final biochemical composition of fruits, as illustrated by the reduction in lipid content in SH dry beans compared to FS beans. This 

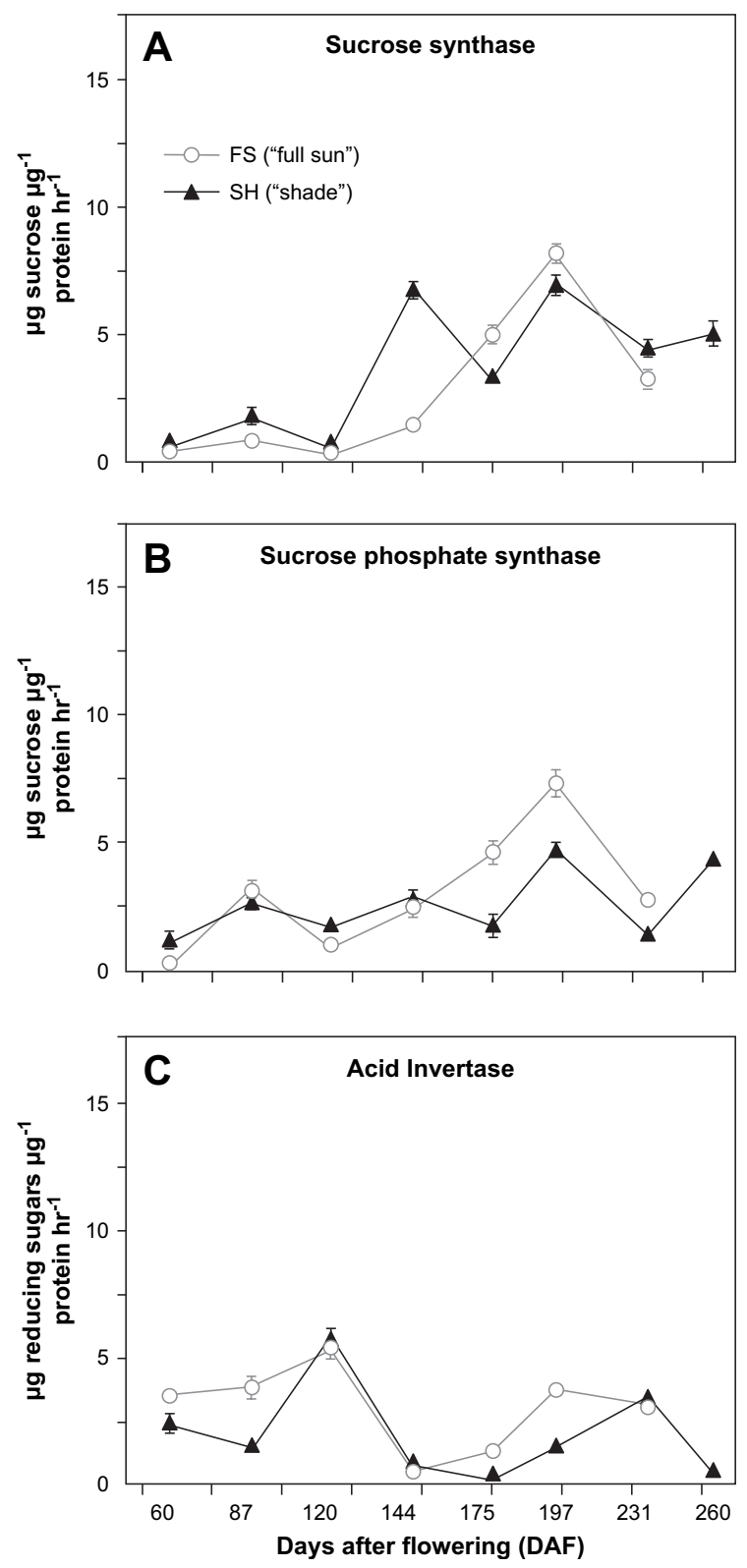

Fig. 3. Enzymatic activities in isolated pericarp tissues during ripening of C. arabica L. cv. IAPAR 59 fruits. Sucrose synthase (A) and sucrose-phosphate synthase (B) activities are expressed as $\mu \mathrm{g}$ sucrose $\mu \mathrm{g}$ protein ${ }^{-1} \mathrm{~h}^{-1}$ during ripening. Acid invertase (C) activity is expressed as $\mu \mathrm{g}$ reducing sugars $\mu \mathrm{g}$ protein $^{-1} \mathrm{~h}^{-1}$. Open circles and closed triangles are for full-sun (FS) and shade $(\mathrm{SH})$, respectively. Error bars indicate standard deviation (SD) of repetitions $(n=3)$.

result contrasts with those of previous studies, which showed a negative correlation between sucrose and lipid content in beans of $C$. arabica $[4,9]$. However, CGA, protein, tannin, trigonelline and caffeine contents did not differ significantly between light regimes. The quantification of additional biochemical compounds (e.g. free amino acids, peptides) of beans could be instrumental in obtaining an in-depth overview of shade effects on coffee bean metabolism.

Another effect of shade on fruit biochemical composition concerns sucrose content, which was lower in both pericarp
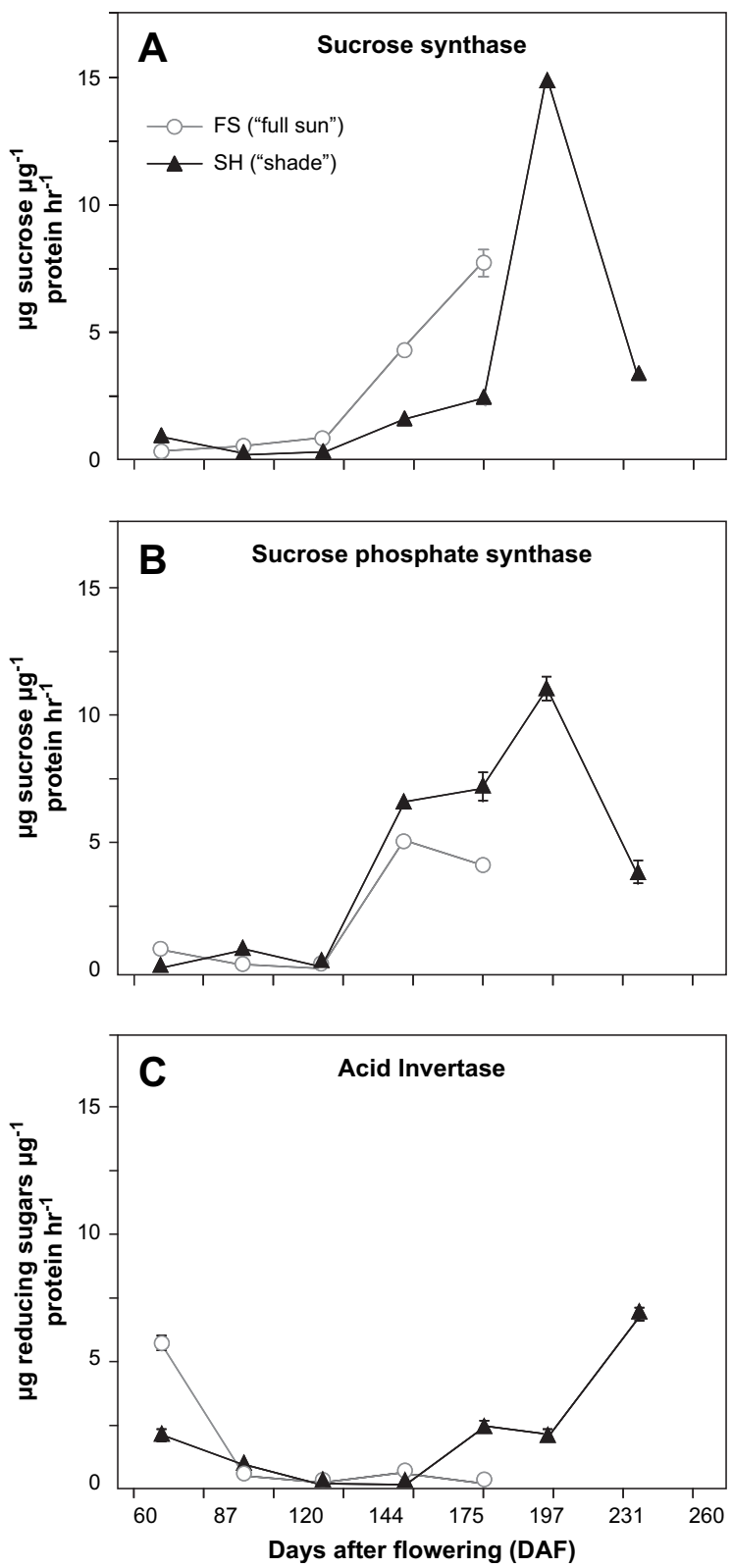

Fig. 4. Enzymatic activities in isolated perisperm tissues during ripening of C. arabica L. cv. IAPAR 59 fruits. Sucrose synthase (A) and sucrose-phosphate synthase (B) activities are expressed as $\mu \mathrm{g}$ sucrose $\mu \mathrm{g}$ protein ${ }^{-1} \mathrm{~h}^{-1}$ during ripening. Acid invertase (C) activity is expressed as $\mu \mathrm{g}$ reducing sugars $\mu \mathrm{g}$ protein ${ }^{-1} \mathrm{~h}^{-1}$. Open circles and closed triangles are for full-sun (FS) and shade $(\mathrm{SH})$, respectively. Error bars indicate standard deviation (SD) of repetitions $(n=3)$.

and endosperm tissues at maturation in plants grown in $\mathrm{SH}$ than in those grown under FS condition, whereas the opposite was observed for reducing sugars. The present data agree with those of Vaast et al. [42] who reported a reduction in sucrose content in the shade environment in beans of $C$. arabica Costa Rica 95 (Catimor) cultivar but contrast with the results observed with the Catuai cultivar, in which a higher sucrose content was observed in beans grown in the shade compared to those grown in full-sun conditions [17]. These discrepancies could be explained by the fact that coffee cultivars respond 

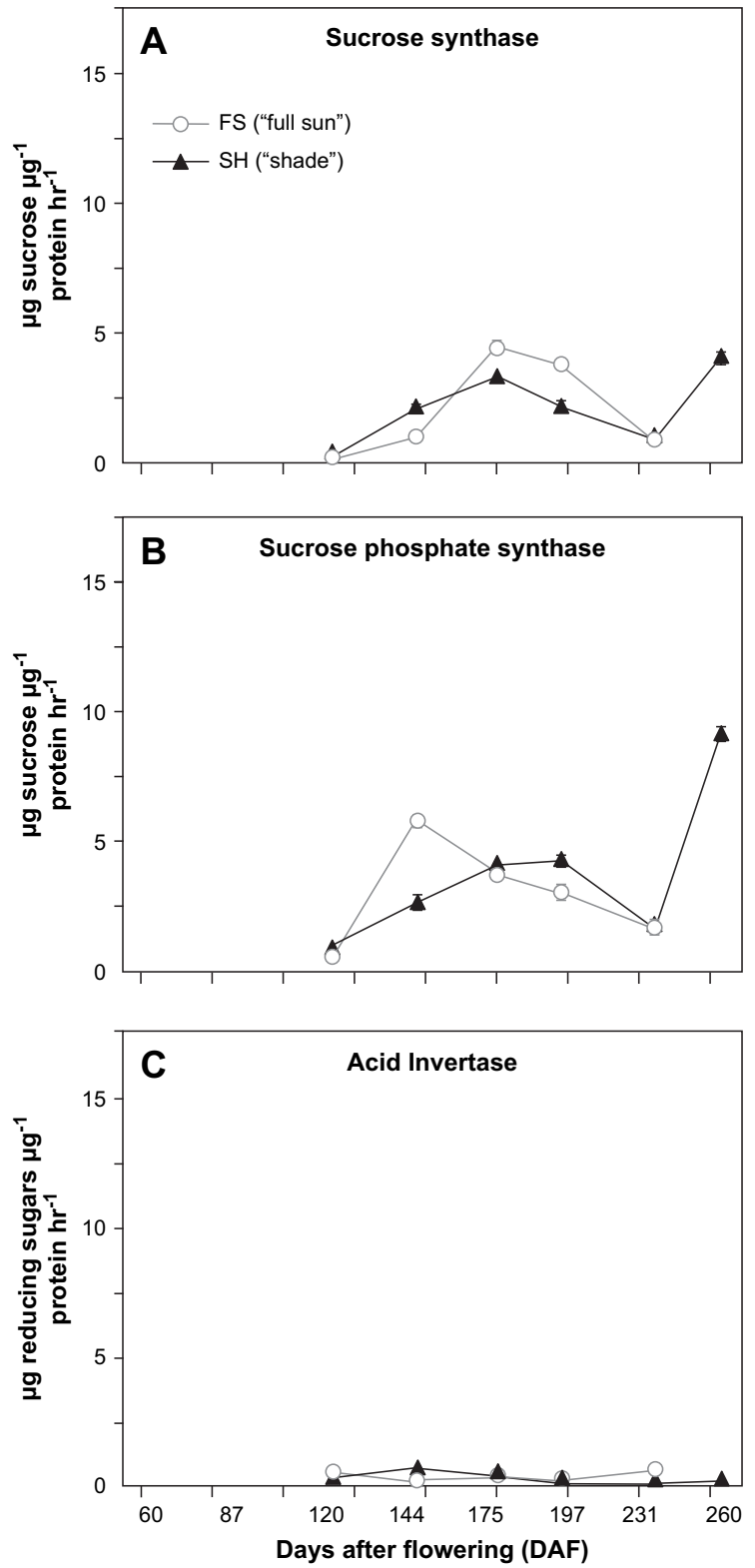

Fig. 5. Enzymatic activities in isolated endosperm tissues during ripening of C. arabica L. cv. IAPAR 59 fruits. Sucrose synthase (A) and sucrosephosphate synthase (B) activities are expressed as $\mu \mathrm{g}$ sucrose $\mu \mathrm{g}$ protein ${ }^{-1} \mathrm{~h}^{-1}$ during ripening. Acid invertase (C) activity is expressed as $\mu \mathrm{g}$ reducing sugars $\mu \mathrm{g}$ protein ${ }^{-1} \mathrm{~h}^{-1}$. Open circles and closed triangles are for full-sun (FS) and shade $(\mathrm{SH})$, respectively. Error bars indicate standard deviation (SD) of repetitions $(n=3)$.

in different ways to similar environmental conditions. In that case, it is worth noting that both IAPAR 59 (this study) and Costa Rica 95 cultivars contain introgressed genome from $C$. canephora via the Timor hybrid while Catuai corresponds to a non-introgressed cultivar of $C$. arabica [37]. In order to know if the reduction in sucrose content in the shade environment observed in introgressed materials (Sarchimor and Catimor) is really an inheritance of $C$. canephora, it should be worth analyzing the effects of light regime on sucrose metabolism in the latter species.

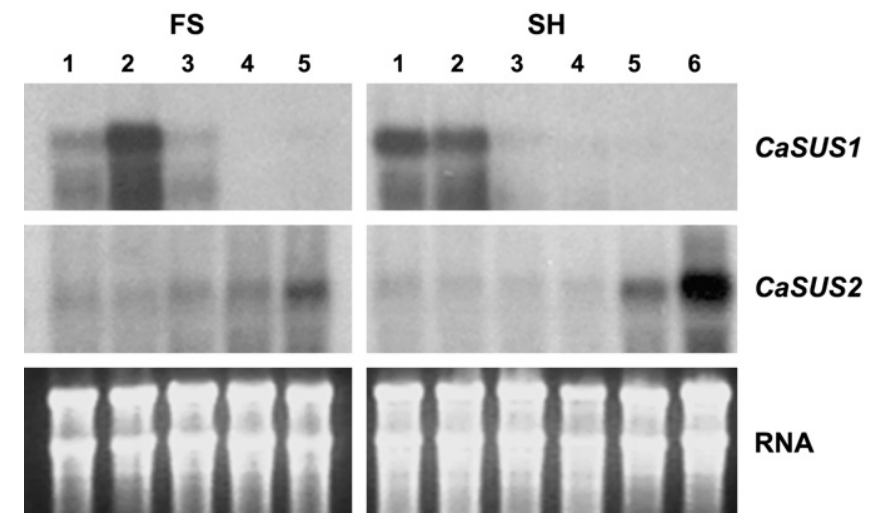

Fig. 6. Expression of CaSUS1 and CaSUS2 genes during endosperm development of fruits grown in full-sun (FS) and shade (SH) conditions. Total RNA isolated from endosperm was separated on a formaldehyde-agarose gel, transferred onto a nylon membrane and hybridized independently with CaSUS1 and CaSUS2 probes at regular developmental stages: lane 1, 120 DAF; lane 2, 144 DAF; lane 3, 175 DAF; lane 4, 197 DAF; lane 5, 231 DAF and lane 6, 260 DAF (only in SH conditions). rRNAs stained by ethidium bromide were used to monitor the equal loading of RNA samples.

It is also known that topography (slope exposure, altitude) and meso-climatic conditions (air temperature and hygrometry) modify bean chemical composition $[4,36]$. Some of the differences reported here could also be explained by post-harvest treatments. For example, Knopp et al. [21] reported that unwashed (dry process, as used in this study) coffee beans usually had higher fructose and glucose contents than those treated by the wet process commonly used in Central America. Together, these considerations make difficult the comparison of beans treated by different post-harvest processes and harvested from plants grown in different climatic conditions.

\subsection{Effects of light regime on enzymatic activities}

Although preliminary, the present results show that activities of several sucrose-metabolizing enzymes are modified by $\mathrm{SH}$ conditions. This is illustrated in mature pericarp and the perisperm, where peaks of SUS and SPS activities were higher in plants grown in SH than in FS conditions. The same was also observed for acid invertase (AI) in the last stages of perisperm. These results also highlight the difficulty in determining clear relationships between changes measured enzymatically in separated tissues and those concerning sugar (reducing sugars and sucrose) contents. For example, high SPS and SUS activities observed in shaded endosperm were not paralleled by a subsequent increase in sucrose content in this tissue. The same was observed for AI activity in shaded perisperm; a concomitant increase in reducing sugars was not observed. In contrast, the negligible AI activity in the shaded endosperm does not explain the increase in reducing sugars in this tissue before the harvest. Such observations, previously reported by Geromel et al. [12], were attributed to intense sucrose degradation, (re)synthesis and transfers occurring between the pericarp, perisperm and endosperm of coffee fruits. However, the action of other sucrose-cleaving enzymes 
$[19,39]$, the regulation of sucrose synthase by sub-cellular localization and the presence of enzymatic activities in cell compartments are difficult to investigate (e.g. apoplastically localized) [28] and cannot be completely ruled out. Nonetheless, the high enzymatic activities retained in the perisperm confirmed the importance of this tissue in controlling coffee bean development $[8,31]$.

The present results also significantly contrast with those previously reported on the same plants grown under FS conditions a year before [12]. For example, SUS activities at harvest in the pericarp and endosperm were two times lower here than those reported in 2002-2003. Alternate bearing of coffee trees, with low and high productivity observed for these plants in 2002-2003 (mean $2340 \mathrm{~kg}$ dried coffee beans ha ${ }^{-1}$ ) and 2003-2004 (mean $3400 \mathrm{~kg} \mathrm{ha}^{-1}$ ), respectively, could explain part of these discrepancies [6]. Environmental factors such as water deficits were reported to alter both the activity and expression of SUS. In addition, in many plant systems where SUS is thought to be involved in meeting the glycolytic demand during water stress, its gene expression and activity are usually increased under drought conditions. This was reported in the leaves of Populus popularis [29] and Arabidopsis thaliana [10]. In contrast, reduced SUS activity and protein content were also reported in response to moderate water stress in soybean nodules [14]. The occurrence of a dry season in 2003-2004 (between 197 and 231 DAF, data not shown) could explain the rapid decline of SUS and SPS activities in pericarp, perisperm and endosperm tissues. Even though physiological analyses (water potential status, leaf net photosynthesis) were not performed during this dry season, we did not observe any noticeable alterations in tissue $\mathrm{FW}$ or reducing sugar/sucrose content during this period. This suggests that water deficit had only limited effects on the accumulated sugar content amassed in coffee fruit tissues.

\subsection{Effects of light regimes on expression of SUS genes}

Shade quantitatively and temporally modifies the expression of SUS-encoding genes in coffee beans. In $C$. arabica, this enzyme is encoded by two different genes, CaSUSI and CaSUS2, which are differentially expressed during endosperm development $[12,24]$. CaSUS1 transcripts accumulate mainly during the early development of endosperm; whereas CaSUS2 transcript levels parallel sucrose synthase activity during the final maturation. The results also clearly show an earlier expression of CaSUS1 and a higher expression of CaSUS2 at maturation in SH as opposed to FS conditions. It is also worth noting that SUS mRNA and protein levels were not closely coupled, as illustrated here by the fact that the maximum SUS1 expression was detected before the peak of SUS activity, which was usually observed at 175 DAF. Such observations were previously reported for SUS during fruit development of $C$. racemosa [13], but also for other plants, such as tomato [44]. This could be attributed to particular regulation processes commonly reported to occur for SUS [46]. For example, it is possible that the accumulated SUS1 transcripts were not translated, as reported for the $S h$ gene, which encodes an
SS1 isoenzyme of SUS in maize seedlings subjected to anaerobic stress [40]. Because SUS1 protein was clearly identified in the endosperm at 118-147 DAF by Western blot analysis [12], this possibility is unlikely. Another explanation is that SUS1 could require post-translational modifications in order to be activated, as previously reported in soybeans [33]. SUS protein is also subjected to reversible phosphorylation that controls its subcellular localization (between the cytosol, plasma membrane and actin cytoskeleton) and consequently activity [46]. Such post-translational modifications do not seem to occur for the CaSUS2 isoform because its transcript paralleled sucrose synthase activity in the last weeks of endosperm development under $\mathrm{SH}$ conditions.

\section{Conclusion}

The present work constitutes the first study detailing the effects of shade on tissue development, sugar metabolism and gene expression in coffee fruits. It clearly demonstrates a relationship between the greater perisperm development occurring early in fruit development and the larger size of mature beans commonly observed under SH conditions. The enhanced SUS activity detected in mature endosperm under $\mathrm{SH}$ conditions, compared with FS, was attributed to the higher expression of CaSUS2 gene. However, these changes were not accompanied by a concomitant increase in sucrose content in mature beans which appeared lower in SH than in FS conditions, suggesting a redirection of sucrose metabolism in other metabolic pathways (e.g. complex polysaccharides) that needs to be further identified.

\section{Acknowledgments}

This project was supported by the Brazilian Consortium for Coffee Research and Development (CBP\&D-Café). P. Marraccini and D. Pot received financial support (DCSUR-BRE-4C5008) from the French Embassy in Brazil. C. Geromel received student fellowships from CAPES-Brazil and FAPESP-São Paulo and P. Mazzafera received a research fellowship from CNPq.

\section{References}

[1] P.T. Alvim, Factors affecting flowering of coffee, J. Coffee Res. 7 (1997) $15-25$.

[2] AOAC, Official Method of Analysis, 15th edition, Association of Official Analytical Chemist, Washington DC, 1990, 1928 pp.

[3] Y. Amor, C. Haigler, S. Johnson, M. Wainscott, D. Delmer, A membraneassociated form of sucrose synthase and its potential role in synthesis of cellulose and callose in plants, Proc. Natl. Acad. Sci. USA 92 (1995) 9353-9357.

[4] J. Avelino, B. Barboza, J.C. Araya, C. Fonseca, F. Davrieux, B. Guyot, C. Cilas, Effects of slope exposure, altitude and yield on coffee quality in two altitude terroirs of Costa Rica, Orosi and Santa María de Dota, J. Sci. Food. Agric. 85 (2005) 1869-1876.

[5] J. Beer, R. Muschler, D. Kass, E. Somarriba, Shade management in coffee and cacao plantations, Agroforest Syst. 38 (1998) 139-164.

[6] B. Bertrand, H. Etienne, B. Guyot, P. Vaast, Year of production and canopy region influence bean characteristics and beverage quality of arabica coffee, In: Proceedings of the 20th International 
Congress on Coffee Research (ASIC), Bangalore, India, 2005, pp. 878-886.

[7] M.M. Bradford, A rapid and sensitive method for the quantitation of microgram quantities of proteins utilizing the principle of protein-dye binding, Anal. Biochem. 2 (1976) 248-254.

[8] R.D. De Castro, P. Marraccini, Cytology, biochemistry and molecular changes during coffee fruit development, Braz. J. Plant Physiol. 18 (2006) 175-199.

[9] F. Decazy, J. Avelino, B. Guyot, J.J. Perriot, C. Pineda, C. Cilas, Quality of different Honduran coffees in relation to several environments, J. Food Sci. 68 (2003) 2356-2361.

[10] A. Déjardin, L.N. Sokolov, L.A. Kleczkowski, Sugar/osmoticum levels modulate differential abscisic acid-independent expression of two stress-responsive sucrose synthase genes in Arabidopsis, Biochem. J. 344 (1999) 503-509.

[11] N. Franck, P. Vaast, M. Génard, J. Dauzat, Soluble sugars mediate sink feedback down-regulation of leaf photosynthesis in field-grown Coffea arabica, Tree Physiol. 26 (2006) 517-525.

[12] C. Geromel, L.P. Ferreira, A.A. Cavalari, L.F.P. Pereira, S.M.C. Guerreiro, D. Pot, T. Leroy, L.G.E. Vieira, P. Mazzafera, P. Marraccini, Biochemical and genomic analysis of sucrose metabolism during coffee (Coffea arabica) fruit development, J. Exp. Bot. 57 (2006) 3243-3258.

[13] C. Geromel, L.P. Ferreira, A. Bottcher, D. Pot, L.F.P. Pereira, T. Leroy, L.G.E. Vieira, P. Mazzafera, P. Marraccini, Sucrose metabolism during fruit development in Coffea racemosa, Ann. Appl. Biol. (2008). doi:10.1111/j.1744-7348.2007.00199.x.

[14] E.M. González, A.J. Gordon, C.L. James, C. Arrese-Igor, The role of sucrose synthase in the response of soybean nodules to drought, J. Exp. Bot. 46 (1995) 1515-1523.

[15] W. Grosch, Volatile compounds, in: R.J. Clarke, O.G. Vitzthum (Eds.), Coffee: Recent Developments, Blackwell Science, Oxford, 2001, pp. 68-89.

[16] B. Guyot, E. Petnga, J.C. Vincent, Analyse qualitative d'un café Coffea canephora var. Robusta en fonction de la maturité. Partie, I. Evolution des caractéristiques physiques, chimiques et organolepiques, Café Cacao Thé 32 (1988) 127-140.

[17] B. Guyot, J.C. Manez, J.J. Perriot, J. Giron, L. Villain, Influence de l'altitude et de l'ombrage sur la qualité des cafés arabica, Plant. Rech. Dév. 3 (1996) 272-280.

[18] K. Herbers, U. Sonnewald, Molecular determinants of sink strength, Curr. Opin. Plant Biol. 1 (1998) 207-216.

[19] N.L. Hubbard, D.M. Pharr, S.C. Huber, Sucrose phosphate synthase and other sucrose metabolizing enzymes in fruits of various species, Physiol. Plant. 82 (1991) 191-196.

[20] A. Komatsu, T. Moriguchi, K. Koyama, M. Omura, T. Akihama, Analysis of sucrose synthase genes in citrus suggests different roles and phylogenetic relationships, J. Exp. Bot. 53 (2002) 61-71.

[21] S. Knopp, G. Bytof, D. Selmar, Influence of processing on the content of sugars in green Arabica coffee beans, Eur. Food. Res. Technol. 223 (2006) 195-201.

[22] C.L. Ky, J. Louarn, S. Dussert, B. Guyot, S. Hamon, M. Noirot, Caffeine, trigonelline, chlorogenic acids and sucrose diversity in wild Coffea arabica, L. and, C. canephora, P. accessions, Food Chem. 75 (2001) 223-230.

[23] S. Lalonde, E. Boles, H. Helmann, L. Barker, J.W. Patrick, W.B. Frommer, J.M. Ward, The dual function of sugar carriers: transport and sugar sensing, Plant Cell 11 (1999) 707-726.

[24] T. Leroy, P. Marraccini, M. Dufour, C. Montagnon, P. Lashermes, X. Sabau, L.P. Ferreira, I. Jourdan, D. Pot, A.C. Andrade, J.C. Glaszmann, L.G.E. Vieira, P. Piffanelli, Construction and characterization of a Coffea canephora BAC library to study the organization of sucrose biosynthesis genes, Theor. Appl. Genet. 111 (2005) 1032-1041.

[25] S.E. Lingle, J.R. Dunlap, Sucrose metabolism in netted muskmelon fruit during development, Plant Physiol. 84 (1987) 386-389.

[26] T. Moriguchi, T. Sananda, S. Yamaki, Seasonal fluctuations of some enzymes relating to sucrose and sorbitol metabolism in peach fruit, J. Am. Soc. Hort. Sci. 115 (1990) 278-281.
[27] R. Muschler, Shade improves coffee quality in sub-optimal coffee zone of Costa Rica, Agroforest Syst. 51 (2001) 131-139.

[28] B. Nguyen-Quoc, C.H. Foyer, A role for 'futile cycles' involving invertase and sucrose synthase in sucrose metabolism of tomato fruit, J. Exp. Bot. 52 (2001) 881-889.

[29] D. Pelah, O. Shoseyov, A. Altman, D. Bartels, Water-stress response in aspen (Populus tremula): differential accumulation of dehydrin, sucrose synthase, GAPDH homologues, and soluble sugars, J. Plant Physiol. 151 (1997) 96-100.

[30] R Development Core Team, R: A Language and Environment for Statistical Computing, R Foundation for Statistical Computing, Austria, Vienna, 2004, ISBN 3-900051-07-0.http://www.R-project.org.

[31] W.J. Rogers, S. Michaux, M. Bastin, P. Bucheli, Changes to the content of sugars, sugar alcohols, myo-inositol, carboxylic acids and inorganic anions in developing grains from different varieties of Robusta (Coffea canephora) and Arabica (C. arabica) coffees, Plant Sci. 149 (1999) $115-123$.

[32] W.J. Rogers, G. Bézard, A. Deshayes, I. Meyer, V. Pétiard, P. Marraccini, Biochemical and molecular characterization and expression of the 11S-type storage protein from Coffea arabica endosperm, Plant Physiol. Biochem. 37 (1999) 261-272.

[33] H. Röhrig, M. John, J. Schmidt, Modification of soybean sucrose synthase by S-thiolation with ENOD40 peptide A, Biochem. Biophys. Res. Commun. 325 (2004) 864-870.

[34] T. Roitsch, M.-C. González, Function and regulation of plant invertases: sweet sensations, Trends Plant Sci. 9 (2004) 606-613.

[35] A.L.P. Sampaio, Classificação e Comércio, in: E.A. Graner, G. Godoy Jr. (Eds.), Manual do Cafeicultor, EDUSP, São Paulo, 1967, pp. 261-320.

[36] E.A. Silva, P. Mazzafera, O. Brunini, E. Sakai, F.B. Arruda, L.H.C. Mattoso, C.R.L. Carvalho, R.C.M. Pires, The influence of water management and environmental conditions on the chemical composition and beverage quality of coffee beans, Braz. J. Plant Physiol. 17 (2005) 229-238.

[37] S.R. Silveira, P.M. Ruas, C.F. Ruas, T. Sera, V.P. Carvalho, A.S.G. Coelho, Assessment of genetic variability within and among progenies and cultivars of coffee using RAPD markers, Gen. Mol. Biol. 26 (2003) 329-336.

[38] N. Somogyi, Notes on sugar determination, J. Biol. Chem. 195 (1952) $19-23$.

[39] A. Sturm, G.-Q. Tang, The sucrose-cleaving enzymes of plants are crucial for development, growth and carbon partitioning, Trends Plant Sci. 4 (1999) 401-407.

[40] E.W. Taliercio, P.S. Chourey, Post-transcriptional control of sucrose synthase expression in anaerobic seedlings of maize, Plant Physiol. 90 (1989) 1359-1364.

[41] P. Vaast, J. Angrand, N. Franck, J. Dauzat, M. Génard, Fruit load and branch ring-barking affect carbon allocation and photosynthesis of leaf and fruit of Coffea arabica in the field, Tree Physiol. 25 (2005) $753-760$.

[42] P. Vaast, B. Bertrand, J.J. Perriot, B. Guyot, M. Génard, Fruit thinning and shade improve bean characteristics and beverage quality of coffee (Coffea arabica, L.) under optimal conditions, J. Sci. Food Agric. 86 (2006) 197-204.

[43] E. Van Handel, Direct microdetermination of sucrose, Anal. Biochem. 22 (1968) 280-283.

[44] F. Wang, A.C. Smith, M.L. Brenner, Temporal and spatial expression pattern of sucrose synthase during tomato fruit development, Plant Physiol. 104 (1994) 535-540.

[45] H. Weber, U. Heim, S. Golombek, L. Borisjuk, U. Wobus, Assimilate uptake and the regulation of seed development, Seed Sci. Res. 8 (1998) 331-345.

[46] H. Winter, S.C. Huber, Regulation of sucrose metabolism in higher plants: localization and regulation of activity of key enzymes, Crit. Rev. Plant Sci. 19 (2000) 31-67.

[47] S.R.T. Yelle, R.T. Chetelat, M. Dorais, J.W. DeVerna, A.B. Bennett, Sink metabolism in tomato fruit: IV. Genetic and biochemical analysis of sucrose accumulation, Plant Physiol. 95 (1991) 1026-1035. 